\title{
Properties of concrete incorporating different nano silica particles
}

\author{
Corresponding author: Musab Alhawat: eng.musab16@gmail.com \\ Ashraf Ashour: a.f.ashour@bradford.ac.uk \\ Amal El-Khoja: a.m.m.el-khoja@bradford.ac.uk \\ School of Engineering, University of Bradford, Bradford BD7 1DP, UK
}

\begin{abstract}
This paper aims to evaluate the influence of surface area and amount of nano silica on the performance of concrete with different water/binder $(\mathrm{w} / \mathrm{b})$ ratios. For this purpose, 63 different mixes were produced using three different types of colloidal NS having various surface areas $\left(52,250\right.$ and $\left.500 \mathrm{~m}^{2} / \mathrm{g}\right)$ and water/binder ratios $(0.4,0.5,0.6)$. By varying the replacement content of NS between $0.25 \%$ and $10 \%$ by weight of cement, the optimum ratio for each type was determined. Compressive strengths at 7 and 28 days, workability and water absorption of concrete mixture with various NS were measured. Moreover, the microstructure of concrete samples was analysed by the scanning electron microscopy and XRD analysis was also carried out for concrete samples. The results indicated that the performance of NS particles in concrete is significantly dependent on its amount and surface area as well as water/binder ratio. The influence of NS on concrete compressive strength was more pronounced at 7 days for all mixes than 28 days due to the ultra-high surface area of NS, accelerating the hydration process. As the $\mathrm{w} / \mathrm{b}$ ratio increases, a better performance was observed for all types of NS used, whilst NS having $250 \mathrm{~m}^{2} / \mathrm{g}$ surface area was found to be the most effective. The optimum amount of NS was ranged between $2 \%$ and $5 \%$, depending on NS surface area; as both NS particle size and $\mathrm{w} / \mathrm{b}$ ratio increase, the optimum amount of NS also increases.
\end{abstract}

Keywords: Nano silica; specific surface area; particle size; compressive strength; optimum ratio; microstructure.

\section{Introduction}

Extensive research is being conducted in attempts to improve the sustainability and performance of concrete for construction industry. In recent years, emerging nanotechnology has gained considerable attention in concrete industry due to the ability of nanomaterials to considerably enhance the mechanical properties of concrete in addition to the possibility of addressing many technical challenges related to concrete materials [1]. Amongst these nanomaterials, nano silica (NS) is considered the most effective since it has high pozzolanic activity, besides its ability in filling concrete pores [2]. It has been reportedly demonstrated that NS particle is not only an environmentally-friendly material, but also can lead to enhancing concrete strength, improving concrete durability by reducing the pore structure and 
voids in the mixture [3]. Moreover, NS has the ability to accelerate the hydration process due to the huge reactive surface of its particles, in addition to the possibility to decrease the segregation and water bleeding of the mixture [4]. In comparison with other cementitious materials such as silica fume, NS found to be more effective in improving concrete strength [5]. All these features are primarily attributed to the ability of its particle size which mostly ranges between $5-100 \mathrm{~nm}$ in filling the micro and nano pores that were left unfilled in the matrix. Furthermore, these particles can act as a nucleus to generate an additional calcium-silicate-hydrate $(\mathrm{C}-\mathrm{S}-\mathrm{H})$, which is the main source of concrete strength [6]. Another possible reason for this improvement could be the high rate of pozzolanic reaction, which is related to the high surface area of these particles. Therefore, hydration process can be enhanced and enormous chemical reactions are predicted. NS can be commercially available in two different forms; namely dry grains or colloidal suspension silica. The latter is synthetically produced in a dispersive solution, and its particles probably easier to mix and disperse, making them more effectively compared to that generated from powders, which is often can be found in a state of agglomeration [7]. However, the potential of agglomeration is still observed, even with colloidal silica [8].

On the other hand, the applications of concrete containing a large quantity of NS or have a huge surface area may result in detrimental effects on concrete performance, causing a higher possibility of agglomeration and poor dispersion [9]. The high surface area could influence the fresh properties of concrete due to the high absorption water molecules at their surface [1]. Furthermore, a very small size of its particles would probably increase the possibility of air bubbles entraining through casting process, which, in turn, prevents the compactness in a proper way [10]. The increase of NS dosage or surface area of its particles may also make the process of dispersion more difficult, and thus specific procedures, for example, ultrasound mixing, are needed, increasing the concrete cost.

The use of NS does not always show similar improvements when it is used in concrete. While some studies indicated that the enhancement in compressive strength could reach over $70 \%$ compared to normal concrete [11], others showed slight improvements or even some reductions in some cases [6]. On the other hand, some researchers concluded that the appropriate percentage of NS ranged between $0.25 \%$ and $5 \%$ of binder weight, while others indicated that concrete performance could be enhanced with higher levels up to about $10 \%[12,13]$. However, at high levels of NS, the possibility of the autogenous shrinkage owing to self-desiccation becomes higher, and hence concrete can be easily cracked. Table 1 demonstrates the variation of findings of 18 investigations from the literature regarding 
the effect of NS on concrete compressive strength. This may be attributed to the difference in NS properties such as surface area, particle size and the state of NS whether dry or colloidal. Other reasons could be associated to the microstructure of concrete due to the change in $w / b$ ratio.

Table 1 . List of studies focusing on the effect of NS on concrete strength.

\begin{tabular}{|c|c|c|c|c|c|c|c|c|}
\hline \multirow[t]{2}{*}{$\begin{array}{l}\text { NS } \\
\text { Type }\end{array}$} & \multirow[t]{2}{*}{$\begin{array}{l}\text { NS Size } \\
(n m)\end{array}$} & \multirow[t]{2}{*}{$\begin{array}{c}\text { SSA } \\
\left(m^{2} / g\right)\end{array}$} & \multirow[t]{2}{*}{$\begin{array}{l}w / b \\
\text { ratio }\end{array}$} & \multirow[t]{2}{*}{$\begin{array}{c}\text { Dosage usage } \\
\text { (\%) }\end{array}$} & \multirow[t]{2}{*}{$\begin{array}{l}\text { Optimum } \\
\text { ratio (\%) }\end{array}$} & \multicolumn{2}{|c|}{$\begin{array}{l}\text { Improvement } \\
\text { (\%) }\end{array}$} & \multirow[t]{2}{*}{ Reference } \\
\hline & & & & & & $7 d$ & $28 d$ & \\
\hline $\mathrm{D}$ & 13 & 200 & 0.48 & 0.3 and 0.9 & 0.9 & 12 & 12 & Du et al., $(2014)^{[3]}$ \\
\hline $\mathrm{D}$ & 15 & 160 & 0.39 & 2,4 and 6 & 4 & - & 19 & Beigi et al., $(2013)^{[14]}$ \\
\hline $\begin{array}{l}\mathrm{C} \\
\mathrm{C}\end{array}$ & $\begin{array}{c}25 \\
5\end{array}$ & $\begin{array}{c}80 \\
500\end{array}$ & $\begin{array}{l}0.53 \\
0.53\end{array}$ & $\begin{array}{c}1.5,4 \text { and } 7 \\
1.5,4\end{array}$ & $\begin{array}{l}7 \\
4\end{array}$ & $\begin{array}{l}28 \\
36\end{array}$ & $\begin{array}{l}30 \\
34\end{array}$ & $\begin{array}{l}\text { Bolhassani \& Samani, } \\
\qquad(2015)^{[15]}\end{array}$ \\
\hline $\mathrm{D}$ & $20-80$ & - & 0.42 & $1.5,3$ and 4.5 & 3 & 4.5 & 43.5 & Serag et al., $(2017)^{[16]}$ \\
\hline $\mathrm{D}$ & 12 & 200 & 0.35 & 0.75 and 1.5 & 1.5 & 25 & 12 & Khaloo et al., (2016) ${ }^{[17]}$ \\
\hline C & $8-20$ & - & 0.4 & $0.5,1.5$ and 3 & 3 & 14 & 25 & $\begin{array}{c}\text { Mujkharjee \& Barai, } \\
\qquad(2015)^{[18]}\end{array}$ \\
\hline $\mathrm{D}$ & $5-40$ & - & 0.35 & $\begin{array}{c}1,2,3,4,5 \\
6,7 \text { and } 8\end{array}$ & 4 & 47.9 & 29.6 & Alam Shah et al., $(2016)^{[19]}$ \\
\hline $\mathrm{C}$ & 20 & - & $\begin{array}{l}0.65 \\
0.50\end{array}$ & $0.5,1$ and 1.5 & $\begin{array}{c}1.5 \\
1\end{array}$ & $\begin{array}{c}30.3 \\
-\end{array}$ & $\begin{array}{c}41 \\
10.6\end{array}$ & Isfahani et al.,(2016) ${ }^{[20]}$ \\
\hline C & $\begin{array}{l}15 \\
80\end{array}$ & $\begin{array}{l}160 \\
560\end{array}$ & 0.4 & $\begin{array}{c}0.5,1,1.5 \text { and } \\
2\end{array}$ & 1 & 21.2 & 18.5 & Najigivi et al., $(2010)^{[21]}$ \\
\hline $\mathrm{D}$ & 15 & 165 & 0.4 & $\begin{array}{c}1,2,3,4 \text { and } \\
5\end{array}$ & 4 & - & 74.3 & Nazari \& Riahi $(2011)^{[11]}$ \\
\hline $\mathrm{D}$ & 10 & 640 & 0.42 & 1 and 3 & 1 & - & 12.3 & Zhang \& Li (2011) ${ }^{[4]}$ \\
\hline C & - & 116 & 0.25 & 0.5 and 2 & 2 & 39 & 30 & Palla et al., $(2017)^{[22]}$ \\
\hline $\mathrm{D}$ & 15 & 640 & 0.4 & $\begin{array}{c}0.5,1,1.5 \text { and } \\
2\end{array}$ & 1 & 21.2 & 21.5 & Najigivi et al., (2013) ${ }^{[1]}$ \\
\hline $\mathrm{D}$ & 15 & 160 & 0.2 & $1,2,3$ and 4 & 3 & 40 & 8 & Ghafari et al., $(2014)^{[23]}$ \\
\hline $\mathrm{D}$ & 20 & 220 & 0.45 & 3,5 and 7 & 9 & 53.2 & 57.2 & Esmaeili \& Andalibi(2008) ${ }^{[24]}$ \\
\hline
\end{tabular}

\section{Research significant}

Despite the fact that the beneficial effect of adding NS particles to concrete has been reported, available research investigations showed a scatter of obtained results due to the large variations of NS particles characteristics utilized by different researchers (e.g. pozzolanic activity, particle size and specific surface area). In this context, research regarding the effect of particle size and surface area of NS on concrete performance is very limited. Another possible cause of this scatter of results could be the 
difference in water/binder ratio $(\mathrm{w} / \mathrm{b})$ considered in the current investigation, thereby affecting the pore size and microstructure of concrete matrix. Moreover, divergent opinions concerning the optimum ratio of the nano-sized particles when they used in concrete. Therefore, the current research aims to investigate the performance of different water/binder ratios and different surface areas of NS on the performance of concrete. Furthermore, the optimum dosage of NS in concrete will be studied.

\section{Experimental programme}

\section{Materials}

The cement used in this research was Portland cement (CEM I/A-LL 52.5R), manufactured by Hanson UK. Coarse aggregate (CA) and fine aggregate (FA) were locally supplied from crushed stone and river sand, respectively. The primary tests for both types of aggregate were conducted and shown in Table 2. Superplasticizers (Master Glenium $315 \mathrm{C}$ ) supplied by BASF was used as needed to maintain the workability of concrete.

Table 2 fine and coarse aggregate properties.

\begin{tabular}{cccc}
\hline Aggregate Type & Specific Gravity & Water absorption (\%) & Bulk density (Kg/m $\mathbf{m}^{\mathbf{3}}$ \\
\hline Fine aggregate & 2.6 & 2.1 & 1580 \\
coarse aggregate & 2.63 & 1.06 & 1600 \\
\hline
\end{tabular}

\section{Nano silica}

Three different commercial NS having different properties were utilized in this research. While the first type has a relatively small surface area $\left(51.40 \mathrm{~m}^{2} / \mathrm{g}\right)$, the other two types were obtained from another supplier with larger specific surface areas $\left(250\right.$ and $\left.500 \mathrm{~m}^{2} / \mathrm{g}\right)$. These products were named; NS-50, NS-250, and NS-500, respectively based on their specific surface area. All the three NS types were in the colloidal suspension silica form. The main properties of these types of NS are described in Table 3, while they are chemically compared to cement components as demonstrated in Table 4. Moreover, Xray diffraction analysis $(\mathrm{XRD})$ was carried out using 2 Theta with a step width of 0.02 for these samples and presented in Fig. 1. The XRD patterns for the three types of NS showed that the broad peak ranged between $11^{\circ}$ and $23^{\circ}$ on the X-ray scale at 2 Theta, which demonstrates the amorphous structure of NS particles with a very low of crystallinity as well as the presence of chemical compound in nano-form $[1,18,25]$ 
Table 3. NS physical properties.

\begin{tabular}{|c|c|c|c|c|c|c|c|}
\hline Name & Colour & $\begin{array}{c}\text { Relative } \\
\text { density }\end{array}$ & $\begin{array}{c}\text { Bulk density } \\
\left(\mathbf{k g} / \mathbf{m}^{\mathbf{3}}\right)\end{array}$ & $\begin{array}{c}\text { Average } \\
\text { particle size } \\
(\mathbf{n m})\end{array}$ & $\begin{array}{c}\mathbf{S S A} \\
\left(\mathbf{m}^{2} / \mathbf{g}\right)\end{array}$ & $\mathbf{p H}$ & $\begin{array}{c}\text { Solid } \\
\text { content of } \\
\mathbf{N S}(\%)\end{array}$ \\
\hline NS-50 & Milky & 1.2 & - & 98.7 & 51.40 & 9.4 & 40 \\
\hline NS-250 & translucent & 1.2 & 1200 & 15 & 250 & 6.8 & 30 \\
\hline NS-500 & Clear cloudy & 1.1 & 1050 & 5 & 500 & 10 & 15 \\
\hline
\end{tabular}

Table 4. Chemical composition (\%) of NS and cement.

\begin{tabular}{|l|c|c|c|c|c|c|c|c|c|}
\hline Component & $\mathrm{SiO}_{2}$ & $\mathrm{CaO}$ & $\mathrm{Al}_{2} \mathrm{O}_{3}$ & $\mathrm{FeO}_{3}$ & $\mathbf{M g O}$ & $\mathrm{SO}_{3}$ & $\mathrm{Na}_{2} \mathrm{O}$ & $\mathbf{R}_{2} \mathrm{O}$ & $\mathbf{L} . \mathbf{O} . \mathbf{I}$ \\
\hline Cement & 20.00 & 63.00 & 5.5 & 0.5 & 1.0 & 3.2 & 0.37 & 0.12 & 2.00 \\
\hline
\end{tabular}

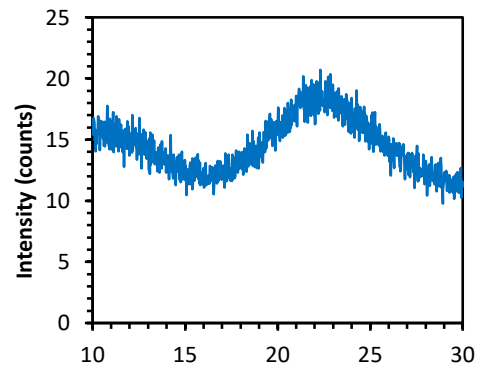

(a)

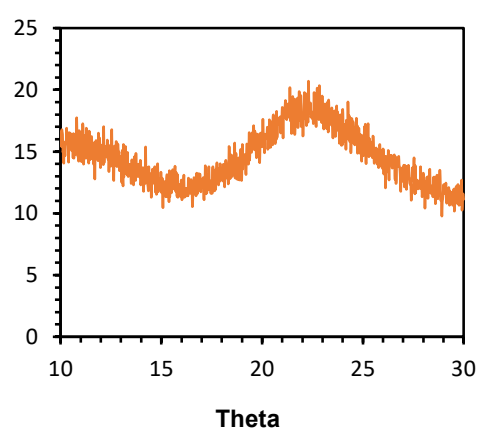

(b)

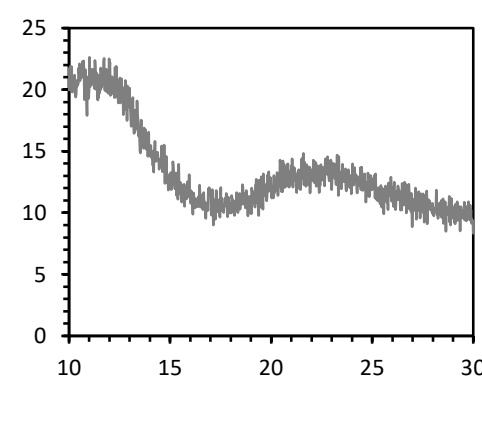

(c)

Fig. 1. XRD analysis for (a) NS-50, (b) NS-250 and (c) NS-500.

\section{Concrete mix design, casting and curing}

To precisely investigate the influence of above mentioned parameters, three different water/binder ratios $(0.4,0.5$ and 0.6$)$ were considered. The concrete mixing procedures, namely, the preparation of materials, mixing, casting and sampling were performed with accordance to BS 1881-125:1986. A 200 I [26]. The mixtures were prepared with various contents of NS including $0.25 \%, 0.50 \%, 0.75 \%, 1 \%$, $1.25 \%, 1.5 \%, 2 \%, 3 \%$ for NS-250 and NS- 500 , and continued with $5 \%$ and $10 \%$ for NS-50. Due to the high surface area of NS-250 and NS- 500, it was very difficult to mix concrete with higher NS dosages than $3 \%$, even with SP. Moreover, concrete mixes with NS ratios of $0.25 \%, 0.75$ and $1.25 \%$ were excluded for $w / b=0.5$ and 0.6 as insignificant changes of compressive strength were recorded for concrete having lower w/b of 0.4 and same NS ratios. Details of concrete mix proportions are given in Table 5. In order to achieve a comparative study, all procedures related to mixing and curing were kept the same for all mixes except replacing cement by the required quantity of NS. It is important to mention that the mixing water was adjusted based on the content of silica and the amount of water present in the solution for each NS type. Initially, NS was mixed separately with the mixing water for 3 min to 
assure the particles of NS are uniformly dispersed. Then, the amount required of SP was mixed with the solution for another $1 \mathrm{~min}$ in order to maintain the workability. Meanwhile, coarse aggregate, cement and sand were mixed in a rotary mixer for $1 \mathrm{~min}$, then, the solution was immediately added to concrete ingredients and mixed for another 2 mins. After casting, all specimens were covered by polyethylene sheets and left at room temperature for 24 hours before they were demoulded. Finally, all specimens were cured in wet conditions until the day of test.

Table 5. Concrete mix proportions.

\begin{tabular}{|c|c|c|c|c|c|c|c|c|}
\hline \multirow[t]{2}{*}{$w / b$ ratio } & \multicolumn{4}{|c|}{ Mix proportions $\left(\mathrm{Kg} / \mathrm{m}^{3}\right)$} & \multirow{2}{*}{ NS (\%) } & \multicolumn{3}{|c|}{ Superplasticiser (\%) } \\
\hline & Cement & Total water & $F A$ & $C A$ & & NS-50 & $N S-250$ & NS-500 \\
\hline \multirow{9}{*}{0.4} & 448 & \multirow{9}{*}{180} & \multirow{9}{*}{664} & \multirow{9}{*}{1180} & 0.25 & 0 & 0.125 & 0.25 \\
\hline & 447 & & & & 0.5 & 0 & 0.25 & 0.5 \\
\hline & 446 & & & & 0.75 & 0.125 & 0.375 & 0.625 \\
\hline & 444.3 & & & & 1.25 & 0.3 & 0.625 & 0.875 \\
\hline & 443.2 & & & & 1.5 & 0.35 & 0.75 & 1 \\
\hline & 441 & & & & 2 & 0.55 & 1 & 1.5 \\
\hline & 436.5 & & & & 3 & 0.75 & 1.5 & 2 \\
\hline & 427.5 & & & & 5 & 1.25 & - & - \\
\hline & 405 & & & & 10 & 2.25 & - & - \\
\hline \multirow[t]{5}{*}{0.5} & 394 & \multirow[t]{5}{*}{200} & \multirow[t]{5}{*}{615} & \multirow[t]{5}{*}{1205} & 1.5 & 0.35 & 0.75 & 1 \\
\hline & 392 & & & & 2 & 0.55 & 1 & 1.5 \\
\hline & 388 & & & & 3 & 0.75 & 1.5 & 2 \\
\hline & 480 & & & & 5 & 1.25 & - & - \\
\hline & 360 & & & & 10 & 2.25 & - & - \\
\hline \multirow{5}{*}{0.6} & 350 & \multirow{5}{*}{210} & \multirow{5}{*}{610} & \multirow{5}{*}{1210} & 0 & 0 & 0 & 0 \\
\hline & 348.25 & & & & 0.5 & 0 & 0.25 & 0.5 \\
\hline & 346.5 & & & & 1 & 0.25 & 0.5 & 0.75 \\
\hline & 344.75 & & & & 1.5 & 0.35 & 0.75 & 1 \\
\hline & 343 & & & & 2 & 0.55 & 1 & 1.5 \\
\hline
\end{tabular}

\section{Testing of specimens}

Experimental testing was mainly focused on the influence of NS on compressive strength as a representative of the mechanical properties of concrete, whilst the transport properties of mixtures was represented by water absorption test. The influence of NS particles on fresh concrete was also discussed in terms of workability by conducting by the slump test according to BS EN 12350-2:2009 [27]. The compressive strength of concrete was performed in accordance with BS EN12390-3, 2009 [28] on cubes $(100 * 100 * 100 \mathrm{~mm})$ after 7 and 28 days of curing. For each mix, three cubes were tested and the mean value was calculated to represent the compressive strength of concrete. In order to investigate the microstructure of concrete containing NS, samples that showed the highest compressive 
strength at 28 days for each type of NS were collected from concrete cubes and prepared for scanning electron microscopy (SEM) images and X-ray diffraction. It is important to mention that the samples prepared for SEM images were coated by some gold atoms in order to be conductive surface. The water absorption was simply conducted using $100 \mathrm{~mm}$ cube specimens in accordance with BS1881$122,2011[29]$.

\section{Results and discussions}

\section{Workability}

The workability of fresh concrete generally decreased with the increase of the specific surface area and content of NS in the mixture. The reduction in workability due to NS particles compared with a control mix was compensated by adding the required amount of superplasticizers (SP), based on the amount and the specific surface area for each type. Several trail mixes were carried out to adjust SP dosages and the required quantity of SP in the mix was considered as an index for the effect of NS on workability as shown in Fig. 2. For $w / b=0.4,18 \mathrm{~mm}$ was reported as a slump value in control concrete made without SP, while the addition of NS-50 needed a negligible amount of SP for most mixes due to the relatively small surface area of NS-50. However, the addition of NS with specific surface area (SSA) of 250 and $500 \mathrm{~m}^{2} / \mathrm{g}$ hugely reduced mixes workability compared to the control mix, and thus it was essential to add SP even for small dosages of NS $[15,21]$. This can be explained by the generation of a layer of adsorbed water molecules around these particles, causing more need of water to fill up the remaining void fraction. However, it was impossible to mix concrete with $5 \%$ and $10 \%$ for NS-250 and NS-500 as the required dosage of SP would have highly exceeded the recommended dosage from the manufacturer (1.2\%). The highly agglomerated state with the increase of those small particles caused the formation of silanol groups $(\mathrm{Si}-\mathrm{OH})$ with firmly-held clusters, may explain the reason behind this remarkable reduction of workability [30]. In addition, the free water in these mixes was not sufficient to complete the hydration process. The reduction in the amount of lubrication water in concrete due to the increase of NS may also cause more entrapped air inside concrete, especially for high NS dosage [3]. It is worth mentioning that the spherical shape of NS particles might slightly minimise frictional forces among the particles [31], nevertheless, this feature was insufficient to encounter the decrease in workability. Results obtained by [32] indicated that the workability of concrete in terms of slump test decreased by $23 \%$ and $38 \%$ when $1 \%$ and $2 \%$ NS, respectively, were added to the concrete the mix. As expected, as $\mathrm{w} / \mathrm{b}$ increased to 0.5 and 0.6 , the workability for control mixtures significantly increased 
to record $80 \mathrm{~mm}$ and $160 \mathrm{~mm}$, respectively, however, the addition of NS remarkably affected the workability for these mixes. It seems that less amount of SP was required to attain workability close to that found in control mix for these $w / b$ ratios compared to that used with $w / b=0.4$, as observed by [30]

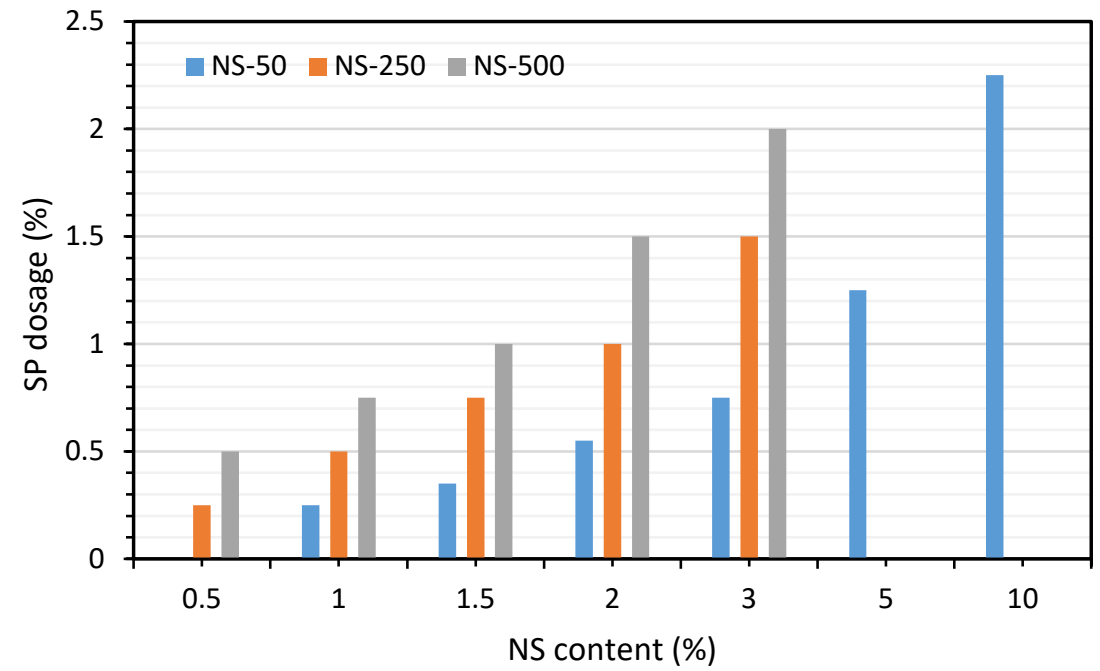

Fig. 2. The required amount of SP (\%) against NS content (\%) in concrete.

\section{Compressive strength}

\section{Effect of nano silica particle size on compressive strength}

Compressive strength is considered as the most important property of concrete as it can be an indicator for other properties. The variation of compressive strength at 7 and 28 days with NS content are presented in Figs. 3 to 5 for different $w / b$ ratios. For $w / b=0.4$, it can be observed that the compressive strengths of concrete containing NS at 7 and 28 days were higher than that of control concrete for all mixes as shown in Fig. 3. However, the addition of small dosages of NS (0, 25, 0.50 and $0.75 \%)$, NS50 showed insignificant improvements in compressive strength compared to control mixture, whilst the same dosages of NS-250 significantly enhanced the strength to reach over $16 \%$ enhancement at just $0.25 \%$, then, it gradually improved with the increase of NS content. This can be supported by the fact that with smaller silica particles, the rate of cement hydration can also be enhanced due to the increase of the heat release by $\mathrm{C}_{3} \mathrm{~S}$-accelerated hydration rate [32]. By adding NS over $1 \%$, more improvements were observed at 7 days for NS-50 to reach the highest strength gain (18.3\%) at $3 \%$, then it slightly decreased to record $12.7 \%$ and $8.4 \%$ at $5 \%$ and $10 \%$ NS, respectively. This reduction in the performance may be ascribed the excess of NS particles, causing no further chemical reaction, and hence the particles only act as fillers without any more contribution to compressive strength [1]. Furthermore, the larger quantities of NS (5\% and 10\%) might enhance the pozzolanic activity, however, 
the amount of cement in the mix was not sufficient to enhance hydration process. In the other words, by replacing cement by 5 and $10 \%$ NS- 50 , the total quantity of NS in the mixture was more than the amount required for hydration process. Hence, the excess particles would leach out without contributing in further reactions [15,33]. On the other hand, NS with SSA $250 \mathrm{~g} / \mathrm{cm}^{2}$ exhibited distinct strength enhancements to attain the maximum strength of $57.12 \mathrm{MPa}$ at 7 days by using $3 \% \mathrm{NS}$, representing approximately $38 \%$ compressive strength enhancement, while $31 \%$ improvement reported after 28 days compared to the control mix. This improvement reflects the ability of NS in refining the pores and enhancing hydration products distribution, particularly at interfacial transition zone (ITZ) as observed by [3]. The findings recorded with NS-500 showed a considerable improvement even with very small dosages, reaching 17.3 and $20.7 \%$ strength gain for concrete have $0.25 \%$ and $0.50 \%$ NS, respectively, even higher than that obtained by NS-250. This is likely to be explained by the "filling gap materials" principle where smaller size particles were more effective in filling small voids in addition to acting as a nucleus for C-S-H gel when cement particles were replaced by a little amount of NS. However, less improvement was noted with the increase of NS-500 content in concrete, which may be justified by the agglomerated state of NS particles, causing the precipitation of $\mathrm{C}-\mathrm{S}-\mathrm{H}$ gel on the surface of agglomerated NS particles, preventing the particles from working individually and reacting with cement grains. Therefore, NS particles on the surface of agglomerate might just react with portlandite, while those inside the agglomeration will stay without reactions. Hence a lesser effect is expected with the increase of replacement ratio compared to that produced with those having smaller SSA $\left(250 \mathrm{~m}^{2} / \mathrm{g}\right)[8]$. On the other hand, NS-50 was less effective on compressive strength at 28days, for example, 3\% NS50 increased the compressive strength to $60.2 \mathrm{MPa}$ compared with that of the control mix (54.8 MPa). The likely reason seems to be related to the large particle size of this type of NS, making it hard to fill the tiny pores in concrete $(w / b=0.4)$. Fig. 4 demonstrates the influence of the three types of NS on concrete made with $w / b=0.5$ after 7 days and 28 days. It can be noted that all concrete containing NS enhanced compressive strength compared to the control mix. Overall, NS-250 was more beneficial for the formation of $\mathrm{C}-\mathrm{S}-\mathrm{H}$ gel than others by achieving the best strength throughout this investigation, while NS-50 generally showed the lowest results. However, the enhancement achieved for $w / b=0.5$ was better than that for concrete having $w / b=0.4$, agreeing with the results of [17], who reported that NS particles are more efficient in lower cement content. As depicted in Fig. 5 , the increase of w/b to 0.6 showed the best effects for the three types at both 7 days and 28 days._This can be attributed to the 
change in the microstructure of concrete matrix corresponding to the change in $w / b$ ratio, thereby the number and size of pores and voids in the matrix would be larger compared to lower w/b ratios. Consequently, more influence of NS was observed with higher w/b ratios since their pores would be easily filled by NS particles, agreeing with other authors [17, 20]. Another reason for this better influence might be related to the influence of $\mathrm{w} / \mathrm{b}$ ratio is the formation of $\mathrm{Ca}(\mathrm{OH})_{2}$ crystal and Ettringite which are abundantly produced in a high $w / b$ ratio, therefore, these unfavourable crystals could be handily absorbed in the existence of NS particles. As a result, more C-S-H gel particles are produced, making concrete matrix denser and more durable $[17,20]$. It is also observed that the increase of NS dosage did not play the main role in affecting the strength of concrete, however, it is greatly directly influenced by the change in the particle size and surface area of NS.

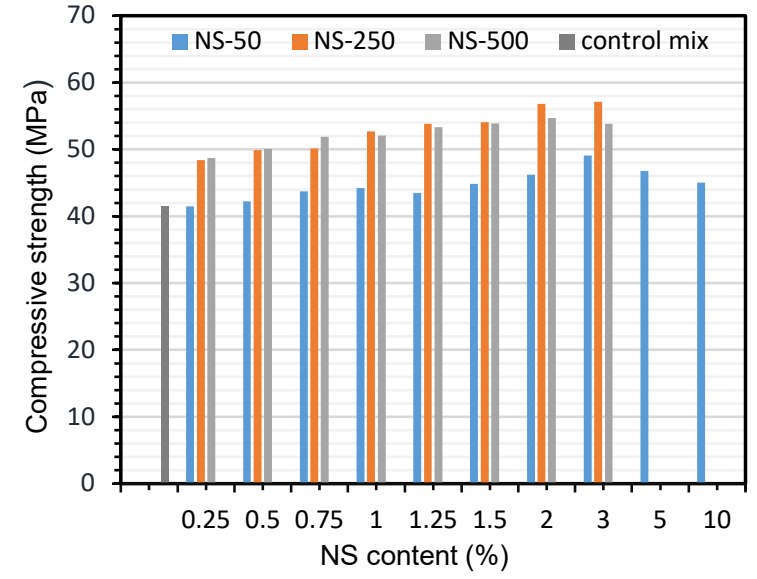

(a)

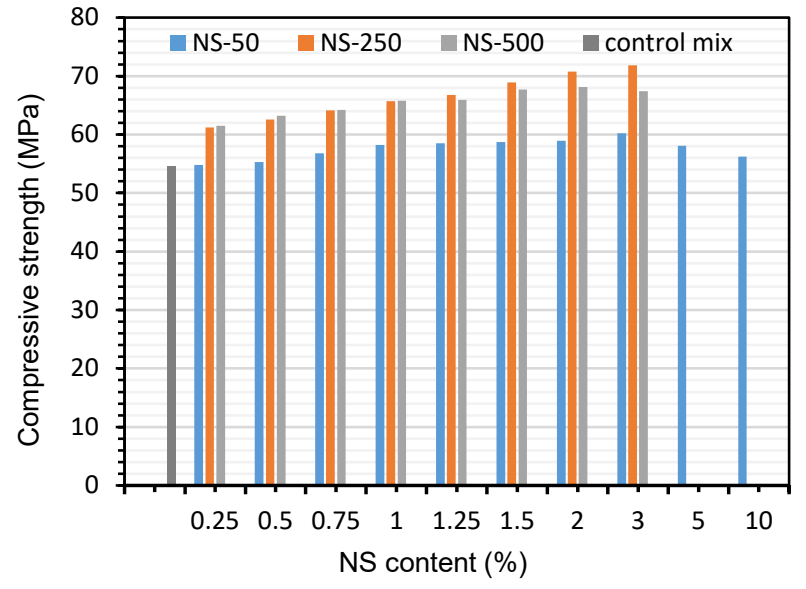

(b)

Fig. 3. Compressive strength of concrete containing NS for $w / b=0.4$ at curing time: (a) 7 days, (b) 28 days.

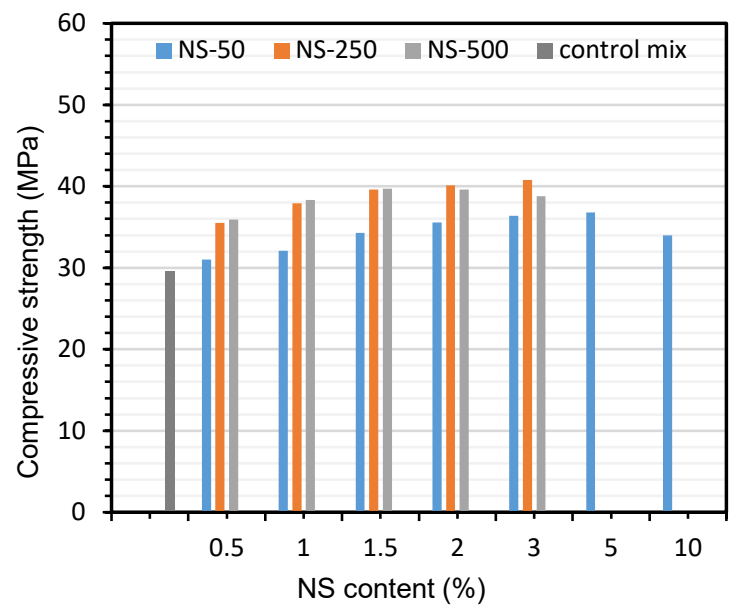

(a)

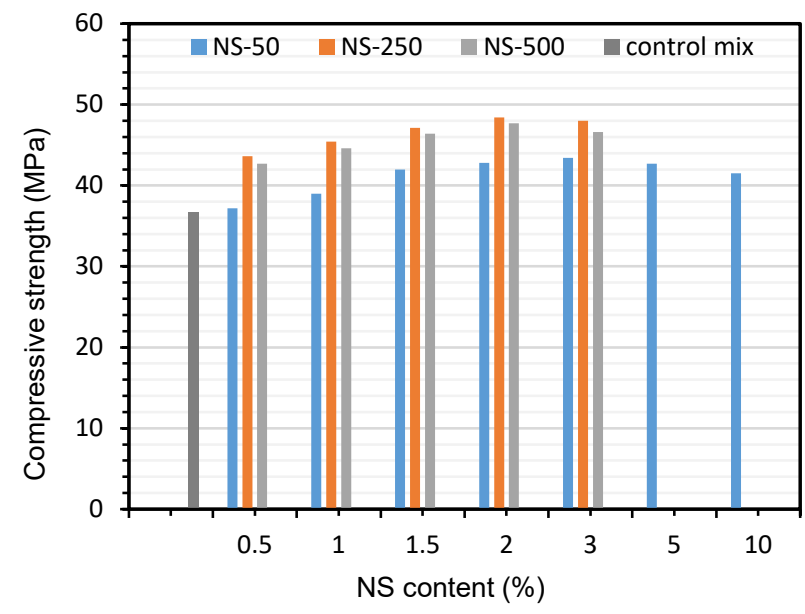

(b)

Fig. 4. Compressive strength of concrete containing NS for $w / b=0.5$ at curing time: (a) 7 days, (b) 28 days. 


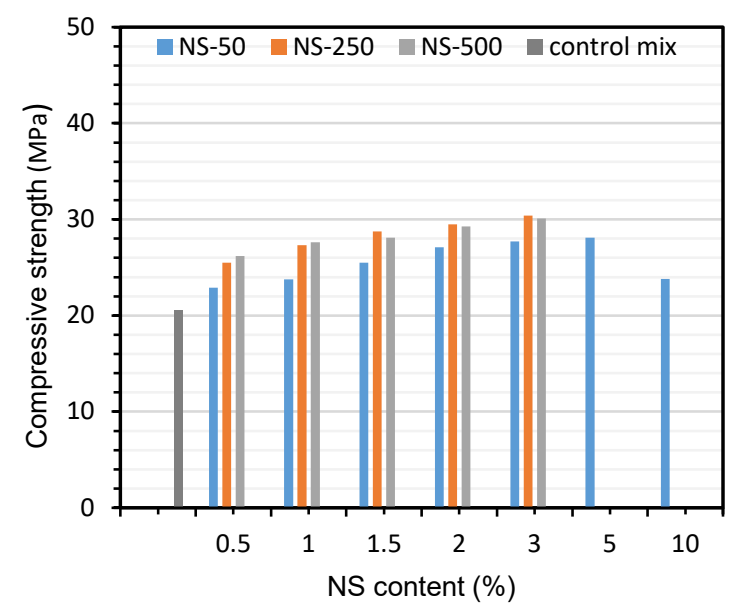

(a)

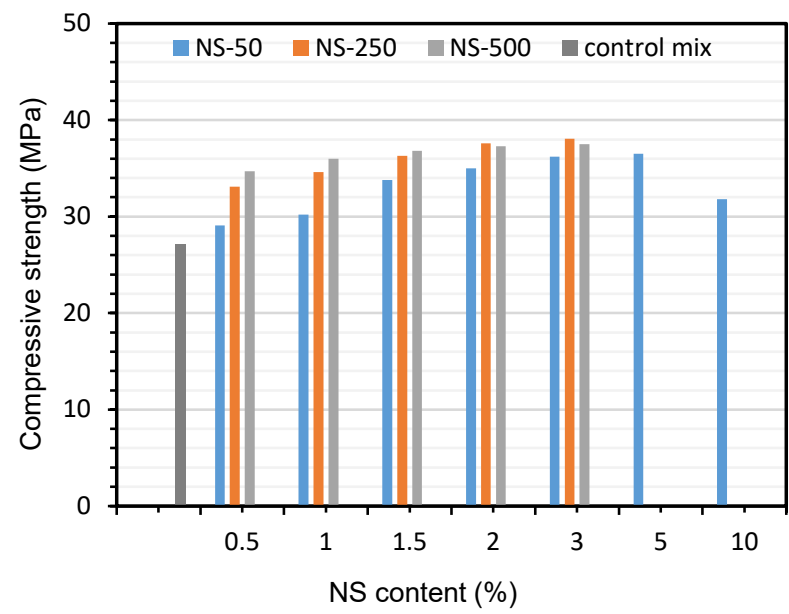

(b)

Fig. 5. Compressive strength of concrete containing NS for $w / b=0.6$ at curing time: (a) 7 days, (b) 28 days.

It can be concluded that amongst the three NS types used, NS-250 achieved the highest enhancement rate for 7 days and 28 days. The possible reason is the suitable size of its particles, which is very efficient in terms of packing ability, pozzolanic activity, and uniform dispersion, and hence the compressive strength distinctly improved for all cases. On the other hand, using a higher w/b showed the best improvement rate with all NS types, which in line with the findings observed by [20], due to the change in concrete microstructure.

\section{Optimum dosages of NS in concrete}

While the low dosage of NS can slightly improve concrete performance, the high concentrations may cause autogenous shrinkage due to the increase of self-desiccation, and consequently, a higher potential of cracking is predicted. It is stated that the optimum amount of NS is directly dependent on the specific surface area of the silica $[34,35]$. From Fig. 6 , it can be noted that the influence of NS-50 on compressive strength was not very strong and did not exceed $18 \%$ at $w / b=0.4$. However, this effect became more influential at $w / b=0.5$, to record the largest concrete compressive strength enhancement at $5 \% \mathrm{NS}$, achieving $25.75 \%$ and at 7 days, then it reduced to $3 \%$ at 28 days. When w/b ratio increased to 0.6 , the rate of enhancement significantly raised for both periods, reaching the optimum value at $5 \%$ at both periods, indicating that with the increase of $w / b$, larger amounts of NS have more influence on concrete strength as more NS particles are needed to densify the matrix [17]. It could be also related to the change in the pore size in concrete microstructure, allowing NS with $98 \mathrm{~nm}$ particle size to fill these voids. Insignificant improvements with concrete having $10 \%$ NS could be ascribed to the fact that the excess of NS may transform some amorphous C-S-H into tobermorite (C5S6H5), which has lesser 
strength properties in addition to the increase of unfavourable silica polymerization [33]. Regarding NS250 , the optimum ratio of NS ranged between $2-3 \%$ NS for all w/b ratios as shown in Fig. 7 . It can be seen that the highest improvement ratio was also obtained with $w / b=0.6$ to record an incredible development at 7 days (48.29\%), then slightly decreased at 28 days recording $40.4 \%$, agreeing with previous investigations [15]. This can be supported by the fact that NS particles are more effective at early ages due to their high pozzolanic activity, leading to increasing the rate of $\mathrm{C}_{3} \mathrm{~S}$ dissolution in the matrix, and therefore the formation of C-S-H gel would be accelerated. With respect to NS-500, the small quantity of NS showed a high rate of improvement, while the increase of NS content in concrete was not very beneficial for compressive strength as shown in Fig. 8. This could be associated with the agglomeration state of their particles, hindering the mix to obtain the maximum packing, and therefore compressive strength slightly increased with the increase of NS content. It can be probably said that the optimum ratio for NS-500 mostly reported at $2 \%$. On the other hand, by reducing $\mathrm{w} / \mathrm{b}$ ratio in the mixture, the lower contents of NS $(0.5 \%$ and $1 \%)$ exhibited a better performance compared with those having a higher $w / b$ ratio [17]. This can be associated with the reduction in hydration degree by decreasing w/b ratio, and therefore smaller amounts of $\mathrm{Ca}(\mathrm{OH})_{2}$ crystals are available to interact with NS particles. In fact, there are two reasons might lead to the reduction in improving the compressive strength when the quantity exceeds the optimum ratio. Firstly, the amount of NS particles in the mixture is higher than that required to react with calcium Hydroxide $\mathrm{Ca}(\mathrm{OH})_{2}$ formed from calcium silicate hydration during hydration process, resulting to leach out the surplus amount of silica $[12,33]$

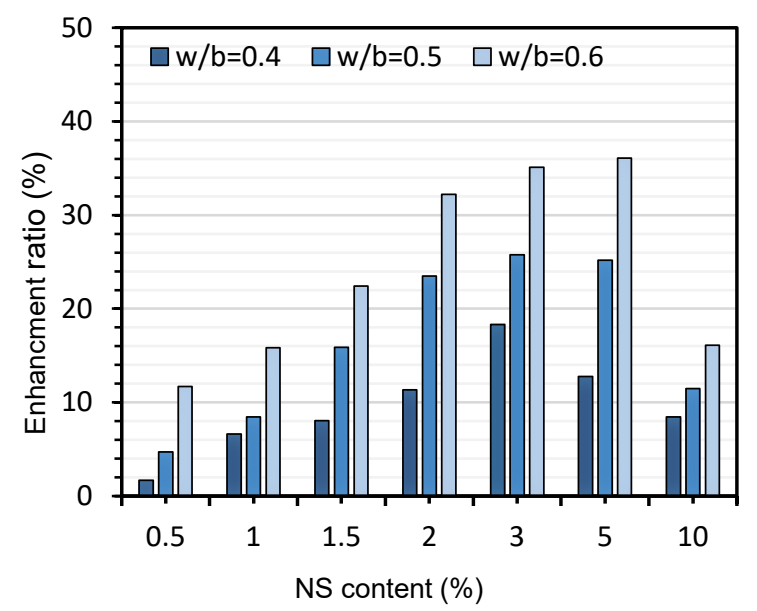

(a)

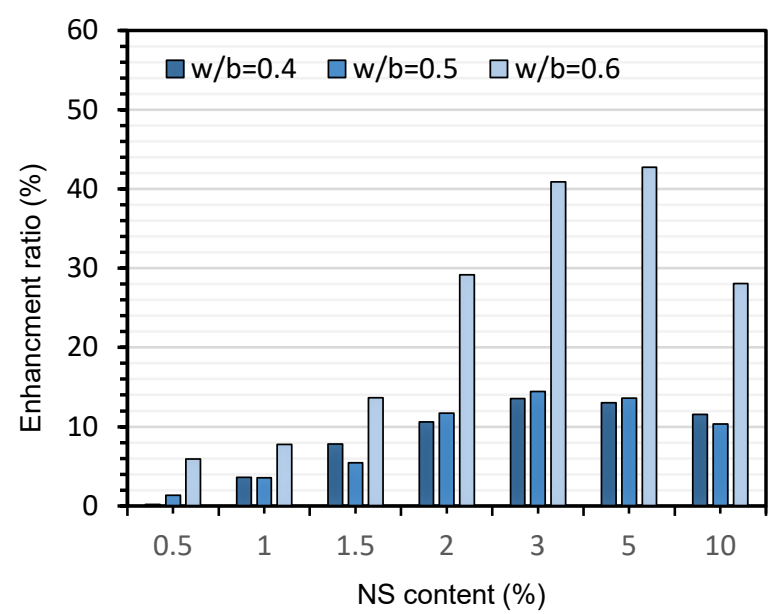

(b)

Fig. 6. Enhancement ratio of concrete mixed with NS-50 for different w/b ratios at: (a) 7days, (b) 28 days. 


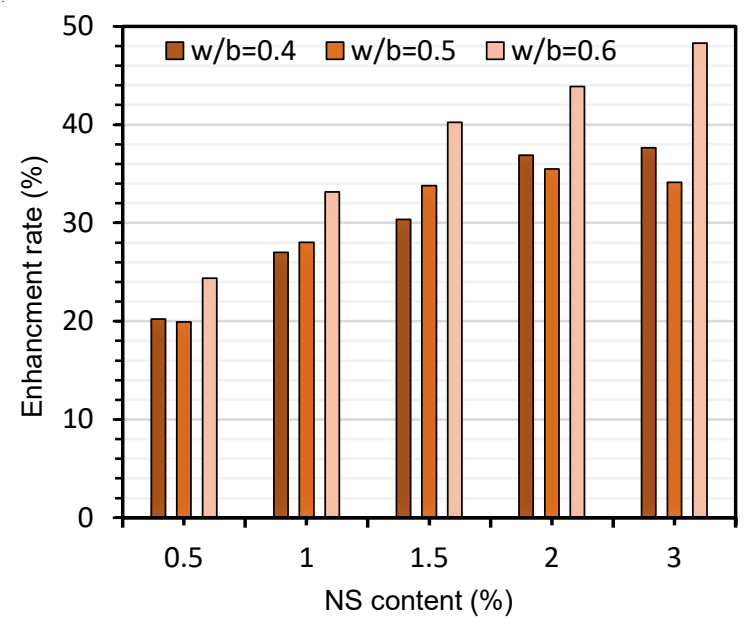

(a)

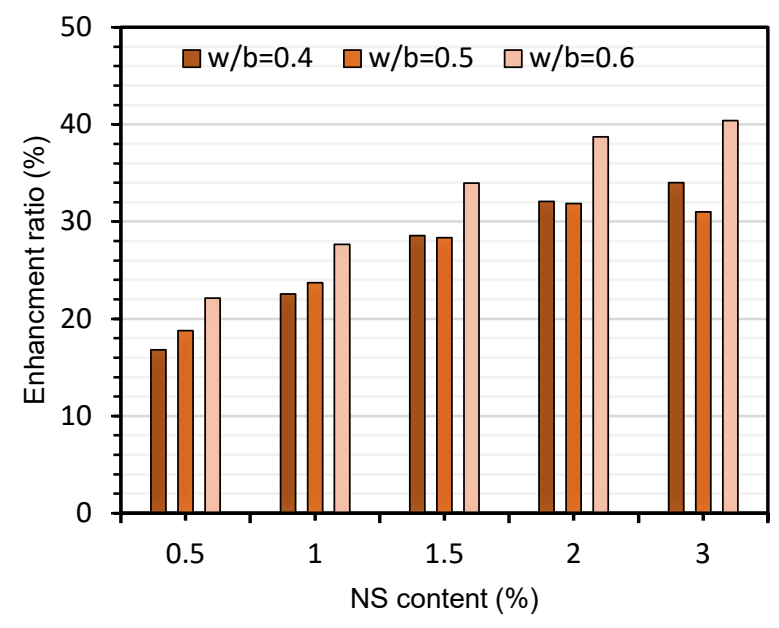

(b)

Fig. 7. Enhancement ratio of concrete mixed with NS-250 for different w/b ratio at: (a) 7days, (b) 28 days.

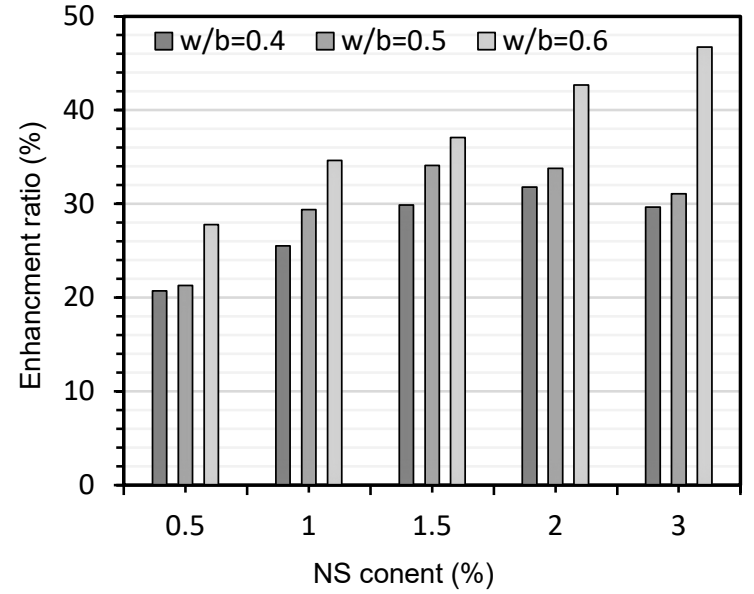

(a)

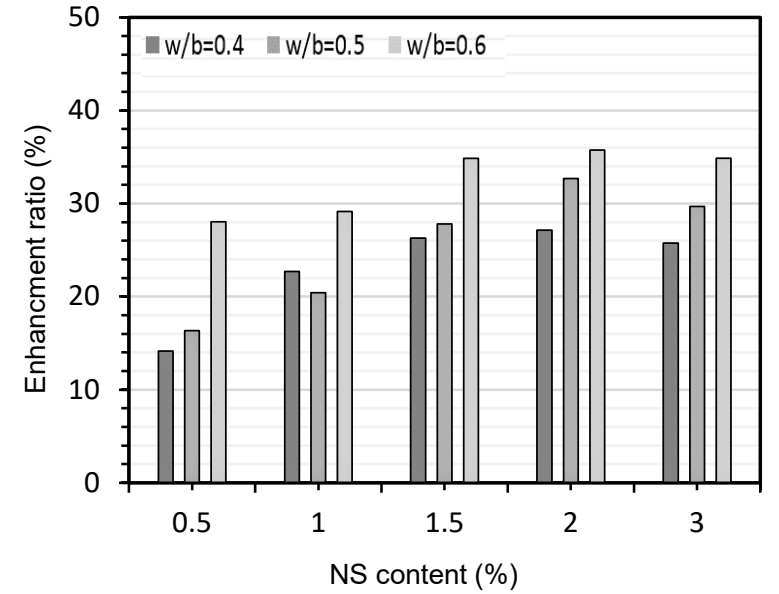

(b)

Fig. 8. Enhancement ratio of concrete mixed with NS-500 for different w/b ratios at: (a) 7days, (b) 28 days.

Based on the obtained results, the optimum ratio of NS in concrete ranges between 2 and $5 \%$ of cement weight as illustrated in Fig. 9, based on its properties and w/b of the mixture. In addition, using a higher quantity of NS over than the optimum ones (2\%-5\%) might lead to the agglomeration state and the deficiency in dispersion of silica particles in the matrix; hence, the particles may become more difficult to uniformly disperse with the increase of its quantity in the mix, leading to forming a weak zone in the matrix, and therefore the strength of concrete decreases. Other investigations $[9,35]$ indicated that the optimum value of NS cannot be constant with specific surface area but it is affected by some factors such as the state of NS (colloidal or dry) and the production method. The results also indicated that the optimum NS ratio in concrete is found to be reduced corresponding to the decrease in w/b ratio, which might be due to lesser Portlandite available in the matrix. 


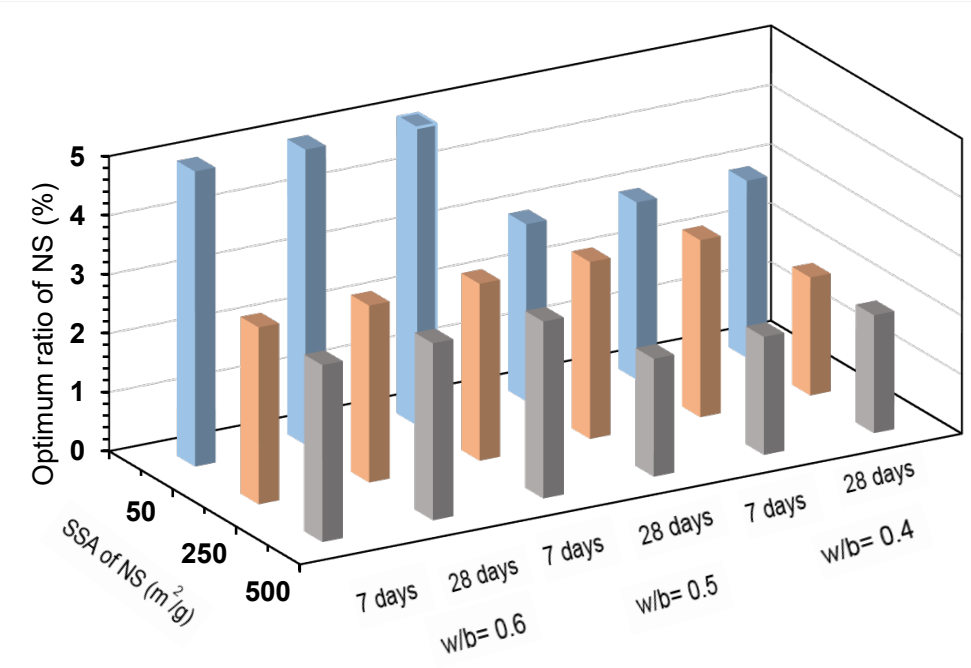

Fig. 9. The influence of $w / b$ ratio on the optimum ratios of NSO

\subsubsection{Water absorption}

Water absorption can be used as a significant indicator for quantifying the transport properties of concrete. The variation of water absorption of concrete for the three types of NS considered is demonstrated in Fig. 10. At w/b=0.4, all types of NS exhibited an increase in water absorption resistance with the increase of NS content to reach $2.8 \%, 2.4 \%$ and 2.52 at $3 \%$ NS compared to $3.7 \%$ for control mix. This reduction is primarily due to the ability of NS in refining the pore size distribution, particularly at the interfacial transition zone (ITZ), and therefore the volume pores in matrix are clearly reduced [3]. It is observed that whilst small quantities of NS effectively reduced entering water into concrete matrix, the increase of NS content slightly increased the resistance against water absorption. This phenomenon might be clarified by the reduction in the unfilled voids in concrete with increasing NS content, especially in concrete made with $w / b=0.4$. As $w / b$ increased to 0.5 , the ability of concrete to absorb water became higher, recording $4.9 \%$ for control mix. However, the use of NS partially hindered this increase by blocking transport paths for water ions by activated NS particles. Therefore, all mixes incorporating NS particles absorbed less water compared to control one due to the improvement of their microstructure, and the ingress of water ions into concrete matrix reduced up to $3.5 \%$ in some cases. With increasing $\mathrm{w} / \mathrm{b}$ to 0.6 , the microstructure of concrete matrix became poorer and rich by connected voids, and hence, water might easily penetrate concrete surface and reach inside concrete. However, the performance of NS particles in preventing concrete from absorbing water became clearer especially for NS-50 to record almost the same influence obtained by the other types (NS-250 and NS-500). 


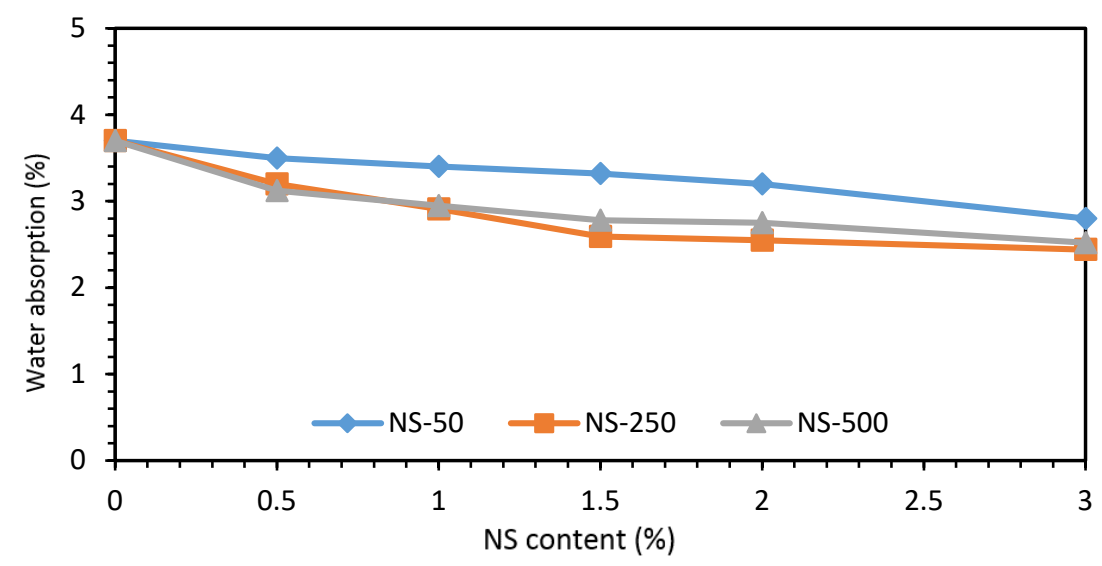

(a)

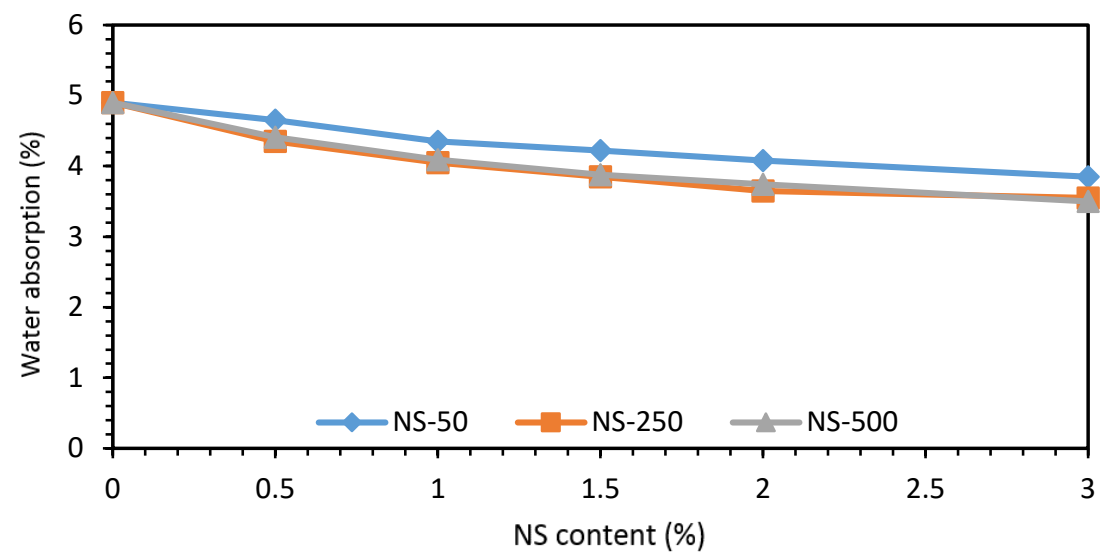

(b)

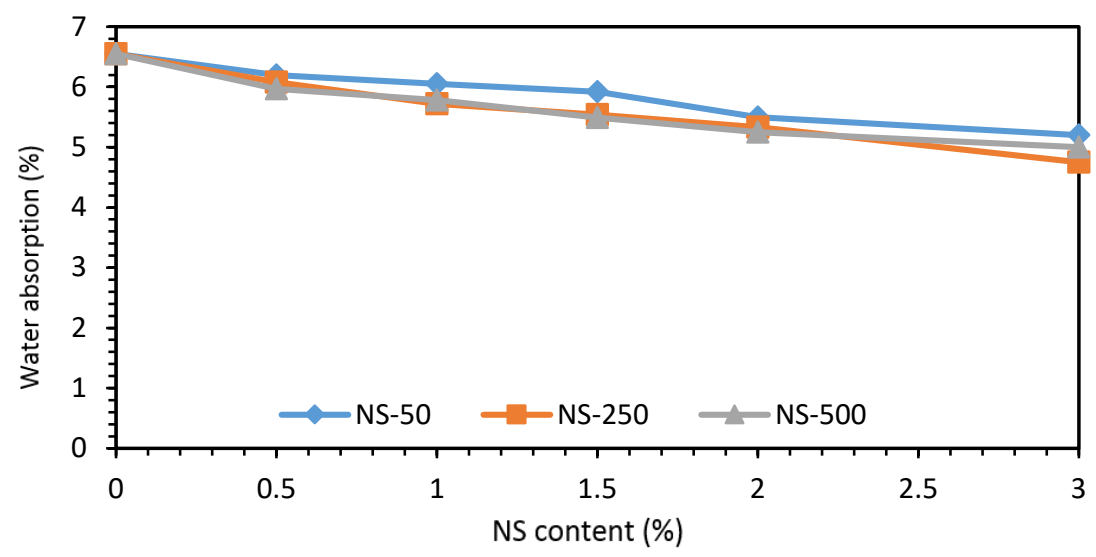

(c)

Fig. 10. Water absorption of concrete containing different types of NS for w/b ratios: (a) $=0.4,(b)=0.5$ and (c) $=0.6$

\section{Microstructural investigations}

\section{SEM analysis}

The microstructure of the samples was analysed by scanning electron microscopy (SEM). The SEM photographs obtained in this study exhibited good correlations with the results obtained for other properties such as compressive strength and water absorption. Fig. 11 shows some selected 
morphological characteristics of the microstructure of concrete made without NS. It can be seen that pores and micro-cracks are easily observed in the microstructure of this mixture. Moreover, some unfavourable crystals, such as $\mathrm{Ca}(\mathrm{OH})_{2}$ exist in the matrix. By incorporating $3 \%$ of $\mathrm{NS}-50$, it can be observed that concrete microstructure was somewhat improved as shown in Fig. 12, indicating the ability of these particles in producing an additional C-S-H gel and filling many pores in the matrix. However, some tiny volume of pores still exist, preventing NS-50 particles from occupying these pores. As observed in Fig. 13 for concrete sample with $3 \%$ of NS-250, the amount of capillary pores was remarkably reduced as the use of NS-250 led to a further densification in the microstructure of concrete mixtures, making the matrix rich with $\mathrm{C}-\mathrm{S}-\mathrm{H}$, which is mainly affected by the shape and size of the particles, particles distribution topology of the matrix and the concentration of particles [7]. Results obtained by [15] revealed that the microstructure of concrete incorporating NS was more uniform, and the high stiffness and chain length of C-S-H increased almost by $20 \%$ compared to the control mix. In comparison with NS-50, the microstructure of NS-250 samples led to a denser microstructure, especially at the interfacial transition zone (ITZ) between aggregate and paste.
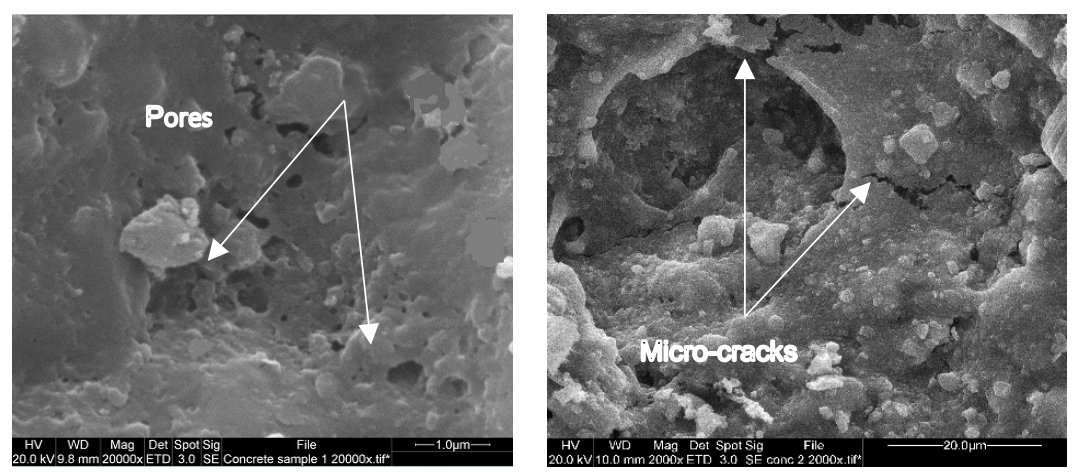

Fig. 11. SEM photographs of concrete made without NS.
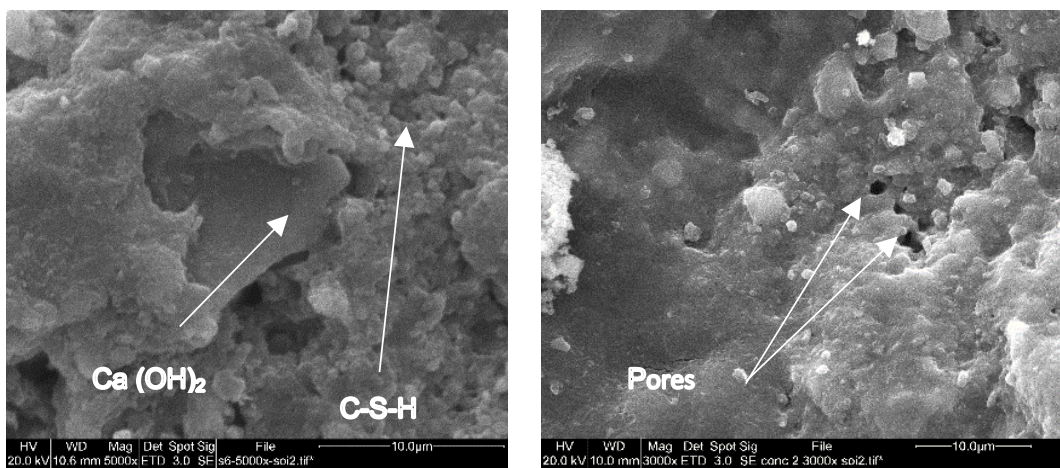

Fig. 12. SEM photographs of concrete made with $3 \%$ of NS-50. 

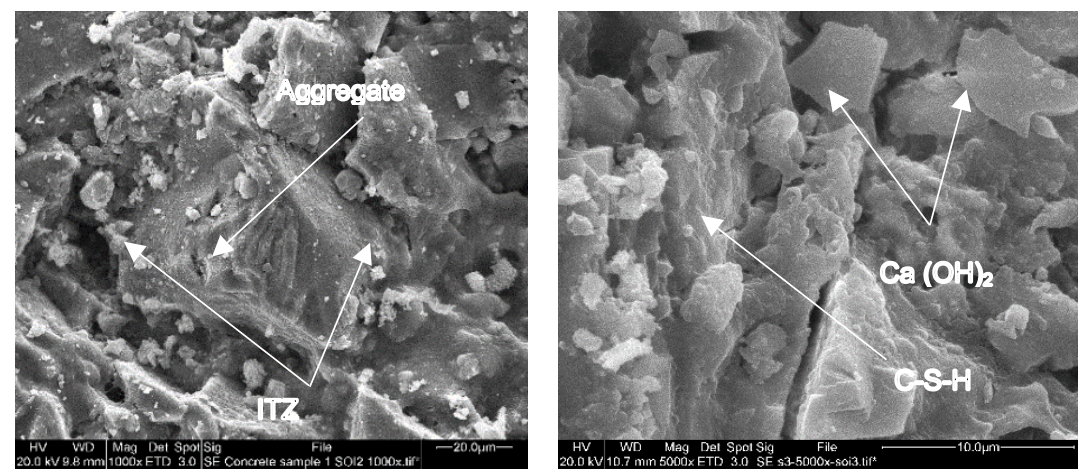

Fig. 13. SEM photographs of concrete made with 3\% NS-250.
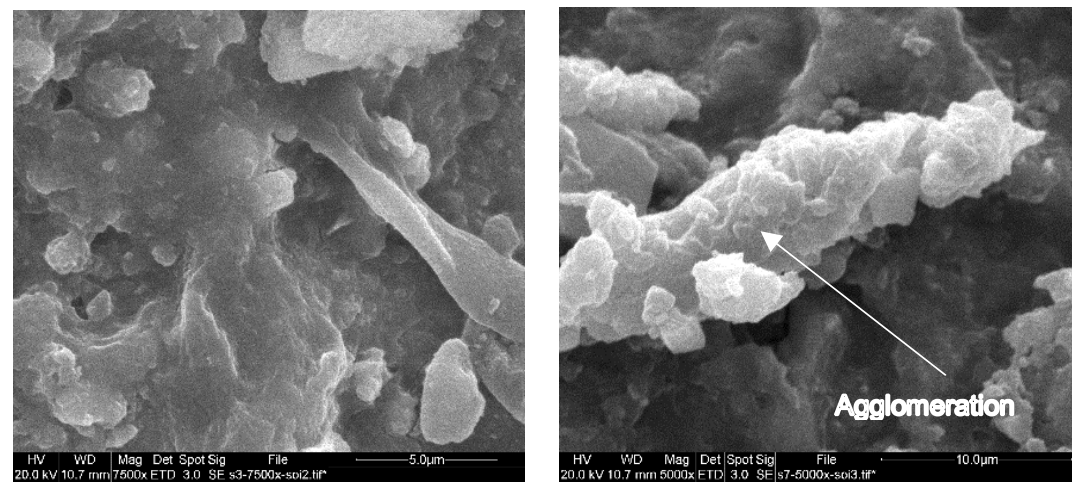

Fig. 14. SEM photographs of concrete made with $2 \%$ of NS-500.

The SEM investigations of NS particles with $2 \%$ of a high specific surface area (NS-500) showed almost similar results with that found in concrete incorporating NS-250 as presented in Fig .14, however, agglomeration state was spotted in some areas due to their ultra high surface area.

\section{XRD analysis}

$\mathrm{XRD}$ analysis was carried out for concrete made with and without NS at the age of 28 days. In order to apply XRD analysis, samples with the highest compressive strength at 28 days were collected from concrete cubes for each type of NS, and finely grounded. These selected samples had $3 \%, 3 \%$ and $2 \%$ of NS-50, NS-250 and NS-500, respectively. As observed from Fig.15, it can be clearly seen that the main crystallization components found in concrete were as follows: quartz, portlandite $\mathrm{Ca}(\mathrm{OH})_{2}$, in addition to un-hydrated grains including Alite $\left(\mathrm{C}_{2} \mathrm{~S}\right)$ and Belite $\left(\mathrm{C}_{3} \mathrm{~S}\right)$. Generally, it is not possible to identify directly the peaks of C-S-H which is the main source of concrete strength by XRD due to the low crystallinity of $\mathrm{C}-\mathrm{S}-\mathrm{H}$, making it difficult for the radiations to be diffracted into peaks. However, portlandite $\mathrm{Ca}(\mathrm{OH})_{2}$ which has an inverse relation with $\mathrm{C}-\mathrm{S}-\mathrm{H}$ can be used to quantify the performance of concrete; if $\mathrm{C}-\mathrm{S}-\mathrm{H}$ is decreased, more $\mathrm{CH}$ would be spotted in XRD results [26, 36]. Evidently, the 


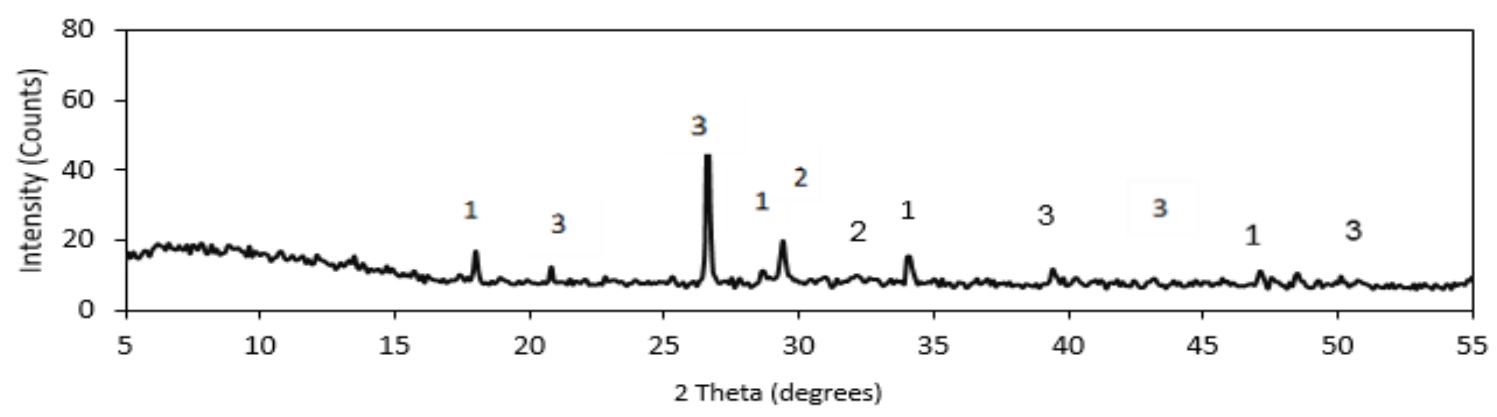

(a)

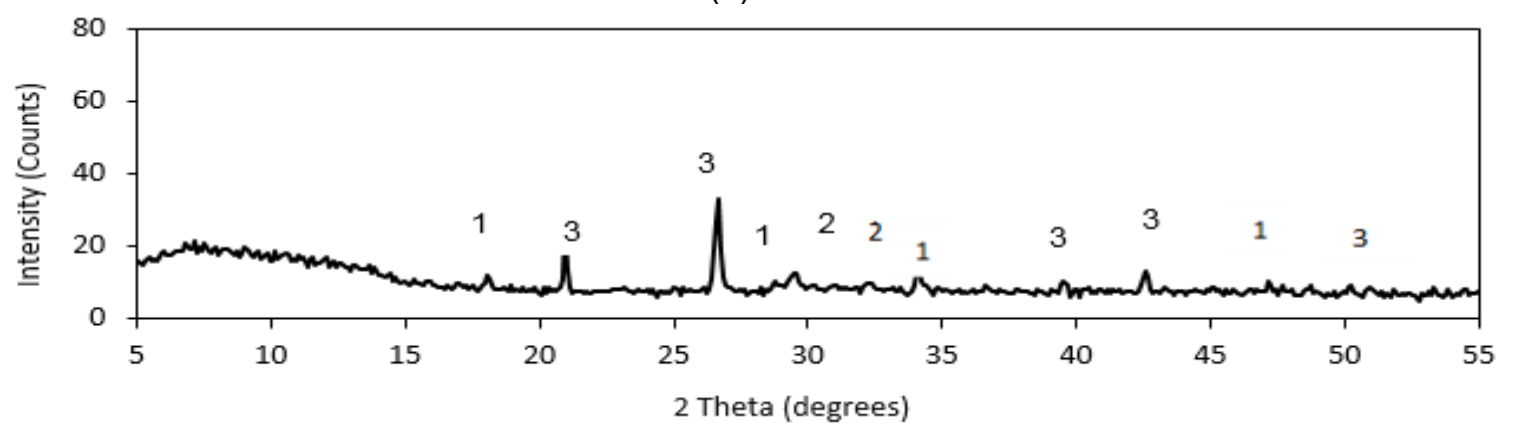

(b)

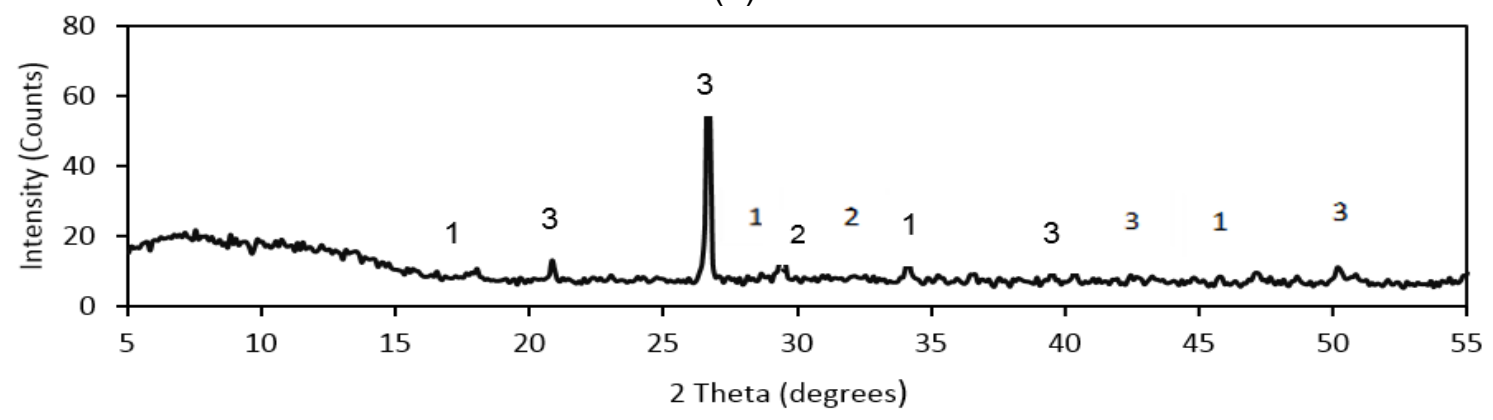

(c)

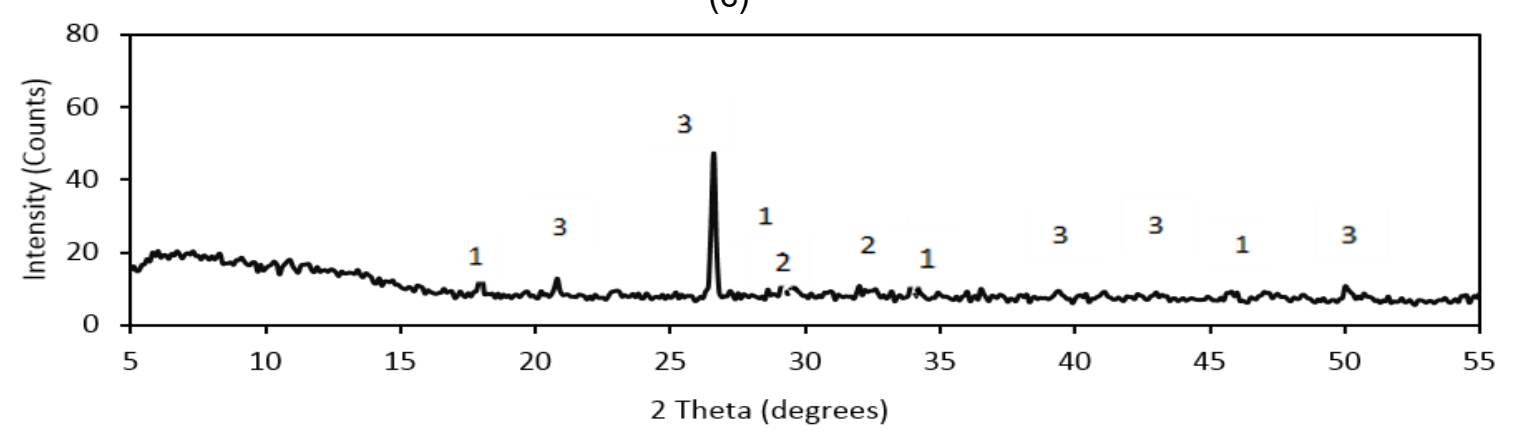

(d)

Fig. 15. XRD spectra of concrete made with and without different types of NS at 28 days: (a) without NS, (b) NS-50, (c) NS-250 and (d) NS-500.

peaks intensity of Portlandite, Alite and Belite were deceased when NS used in concrete for all samples containing NS compared to the control one. This is mainly attributed to the high pozzolanic activity of 
NS particles, in addition to its ability in consuming $\mathrm{Ca}(\mathrm{OH})_{2}$ particles producing an additional amount of C-S-H gel, which is the main source of concrete strength [17]. The reduction in the peaks of un-hydrated grains $\left(\mathrm{C}_{3} \mathrm{~S}\right.$ and $\left.\mathrm{C}_{2} \mathrm{~S}\right)$ indicated the efficiency of NS particles in the reaction with these grains and improving hydration process. It can be also noted that NS-250 showed the lowest intensity values of $\mathrm{Ca}(\mathrm{OH})_{2}$, confirming the previous results obtained from compressive strength test. The main peaks for all samples were identified as quartz peaks due to the large number of aggregate particles whether fine or coarse containing quartz. The increase of quartz peaks was noticeable when NS added to the matrix, especially with NS-250 and NS-500 indicating the presence of NS in the matrix.

\section{Conclusions}

This paper presented the influence of surface area and dosage of NS on concrete properties. The following conclusions may be drawn from the experimental results:

- Influence of NS on concrete workability is mainly governed by the specific surface area of NS and partially affected by the w/b ratio of concrete mix. While the increase of specific surface area could hugely decrease concrete workability, the increase of $\mathrm{w} / \mathrm{b}$ seemingly leads to reducing the demand water for mixing concrete incorporating NS through hydration process.

- The influence of NS on concrete compressive strength was more pronounced at the early age ( 7 days) for all mixes compared with that at 28 days, corresponding to the acceleration of hydration process due to the ultra-high surface area of these materials.

- The compressive strength of concrete is directly influenced by the change of the specific surface area of NS. Amongst the three used types of NS, NS with SSA of $250 \mathrm{~m}^{2} / \mathrm{g}$ showed the highest enhancement rate of compressive strength at 7 and 28 days, followed by NS with SSA of $500 \mathrm{~m}^{2} / \mathrm{g}$, whilst using NS with SSA of $51.4 \mathrm{~m}^{2} / \mathrm{g}$ was less advantageous for all mixes.

- The increase of $w / b$ ratio leads to improving the performance of NS particles in the matrix due to the accessibility of NS in filling the voids available in concrete made with higher w/b ratio.

- The optimum replacement ratio for each type of NS is greatly associated with the particles reactivity and agglomeration state. Apparently, it becomes higher since the size of NS particles is larger, however, it is found to be ranging between $2 \%$ and $5 \%$. The optimum ratio 
of NS also related to $\mathrm{w} / \mathrm{b}$ ratio. It is found to be increased with the increase of $\mathrm{w} / \mathrm{b}$ ratio corresponding to the growth of pores and calcium hydroxide in the matrix.

- The water absorption considerably decreased when NS particles were used in concrete, especially with higher $w / b$ ratios.

- Results obtained by XRD analysis and SEM investigation confirmed the contribution of the use of NS as a partial replacement to cement in improving the performance of concrete by enhancing the pore structure of concrete.

\section{Acknowledgments}

The authors wish to thank BASF and AkzoNobel Companies for providing nano silica used in this present study. The authors also gratefully acknowledge Hanson Ltd, UK for suppling cement require in this study.

\section{References}

[1]. Givi, A.N., et al., Influence of 15 and 80 nano-SiO2 particles addition on mechanical and physical properties of ternary blended concrete incorporating rice husk ash. Journal of Experimental Nanoscience, 2013. 8(1): p. 1-18.

[2]. Sanchez, F. and K. Sobolev, Nanotechnology in concrete-a review. Construction and building materials, 2010. 24(11): p. 2060-2071.

[3]. Du, H., S. Du, and X. Liu, Durability performances of concrete with nano-silica. Construction and Building Materials, 2014. 73: p. 705-712.

[4]. Zhang, M.-h. and H. Li, Pore structure and chloride permeability of concrete containing nanoparticles for pavement. Construction and Building Materials, 2011. 25(2): p. 608-616.

[5]. Mondal, P., et al., Comparative study of the effects of microsilica and nanosilica in concrete. Transportation research record: journal of the transportation research board, 2010(2141): p. 6-9.

[6]. Ji, T., Preliminary study on the water permeability and microstructure of concrete incorporating nano-SiO 2. Cement and Concrete Research, 2005. 35(10): p. 1943-1947.

[7]. Zeidan, M.S., Performance of concrete incorporating colloidal nano-silica. 2013.

[8]. Kong, D., et al., Influence of nano-silica agglomeration on microstructure and properties of the hardened cement-based materials. Construction and Building Materials, 2012. 37: p. 707-715.

[9]. Haruehansapong, S., T. Pulngern, and S. Chucheepsakul, Effect of the particle size of nanosilica on the compressive strength and the optimum replacement content of cement mortar containing nano-SiO 2. Construction and Building Materials, 2014. 50: p. 471-477.

[10]. Said, A.M., et al., Properties of concrete incorporating nano-silica. Construction and Building Materials, 2012. 36: p. 838-844.

[11]. Nazari, A. and S. Riahi, The effects of SiO2 nanoparticles on physical and mechanical properties of high strength compacting concrete. Composites Part B: Engineering, 2011. 42(3): p. 570578.

[12]. Li, X., et al., Surface-modification in situ of nano-SiO 2 and its structure and tribological properties. Applied Surface Science, 2006. 252(22): p. 7856-7861.

[13]. Gaitero, J., I. Campillo, and A. Guerrero, Reduction of the calcium leaching rate of cement paste by addition of silica nanoparticles. Cement and Concrete Research, 2008. 38(8): p. 1112-1118. 
[14]. Beigi, M.H., et al., An experimental survey on combined effects of fibers and nanosilica on the mechanical, rheological, and durability properties of self-compacting concrete. Materials \& Design, 2013. 50: p. 1019-1029.

[15]. Bolhassani, M. and M. Samani, Effect of type, size, and dosage of nanosilica and microsilica on properties of cement paste and mortar. ACI Materials Journal, 2015. 112(2).

[16]. Serag, M.I., et al., EFFECT OF NANO SILICA ON CONCRETE BOND STRENGTH MODES OF FAILURE. International Journal, 2017. 12(29): p. 2892-2899.

[17]. Khaloo, A., M.H. Mobini, and P. Hosseini, Influence of different types of nano-SiO 2 particles on properties of high-performance concrete. Construction and Building Materials, 2016. 113: p. 188-201.

[18]. Mukharjee, B.B. and S.V. Barai, Characteristics of sustainable concrete incorporating recycled coarse aggregates and colloidal nano-silica. Advances in concrete construction, 2015. 3(3): p. 187-202.

[19]. Shah, M.M.A., E. Balaji, and G.A.M. Pandian, Experimental study on mechanical properties of high strength concrete using Nano-Silica. 2016.

[20]. Torabian Isfahani, F., et al., Effects of nanosilica on compressive strength and durability properties of concrete with different water to binder ratios. Advances in Materials Science and Engineering, 2016. 2016.

[21]. Givi, A.N., et al., The effects of lime solution on the properties of SiO2 nanoparticles binary blended concrete. Composites Part B: Engineering, 2011. 42(3): p. 562-569.

[22]. Palla, R., et al., High strength sustainable concrete using silica nanoparticles. Construction and Building Materials, 2017. 138: p. 285-295.

[23]. Ghafari, E., et al., The effect of nanosilica addition on flowability, strength and transport properties of ultra high performance concrete. Materials \& Design, 2014. 59: p. 1-9.

[24]. Esmaeili, J. and K. Andalibi, Investigation of the effects of nano-silica on the properties of concrete in comparison with micro-silica. International Journal of Nano Dimension, 2013. 3(4): p. 321-328.

[25]. Chithra, S., S.S. Kumar, and K. Chinnaraju, The effect of Colloidal Nano-silica on workability, mechanical and durability properties of High Performance Concrete with Copper slag as partial fine aggregate. Construction and Building Materials, 2016. 113: p. 794-804.

[26]. BS 1881-125:1986. Testing Concrete-Part 125: Methods for Mixing and Sampling Fresh Concrete in the Laboratory. London: BSI.

[27]. BS EN 12350-2:2009: Testing fresh concrete. Slump-test. 2009, British Standards Institute.

[28]. BS EN 12390-3:2009: Testing hardened concrete. Compressive strength of test specimens. 2009, British Standards Institute.

[29]. BS 1881-122:2011: Testing concrete. Method for determination of water absorption. 2011, British Standards Institute.

[30]. Hosseini, P., A. Booshehrian, and A. Madari, Developing concrete recycling strategies by utilization of nano-SiO2 particles. Waste and Biomass Valorization, 2011. 2(3): p. 347-355.

[31]. He, Q., et al., Size-controlled synthesis of monodispersed mesoporous silica nano-spheres under a neutral condition. Microporous and Mesoporous Materials, 2009. 117(3): p. 609-616.

[32]. Li, W., et al., Effects of nano-particles on failure process and microstructural properties of recycled aggregate concrete. Construction and Building Materials, 2017. 142: p. 42-50.

[33]. Najigivi, A., A. Khaloo, and S.A. Rashid, Investigating the effects of using different types of SiO2 nanoparticles on the mechanical properties of binary blended concrete. Composites Part B: Engineering, 2013. 54: p. 52-58.

[34]. Parida, S., Effect of Nano Silica on the Compressive Strength of Concrete. 2015.

[35]. Land, G. and D. Stephan, The influence of nano-silica on the hydration of ordinary Portland cement. Journal of materials science, 2012. 47(2): p. 1011-1017.

[36]. Shaikh, F., S. Supit, and P. Sarker, A study on the effect of nano silica on compressive strength of high volume fly ash mortars and concretes. Materials \& Design, 2014. 60: p. 433-442. 